\title{
Mathematical Analysis of the Flow of Hyaluronic Acid Around Fascia During Manual Therapy Motions
}

Max Roman, PhD; Hans Chaudhry, PhD; Bruce Bukiet, PhD; Antonio Stecco, MD; and Thomas W. Findley, MD, PhD

From the Department of Biomedical Engineering (Drs Roman and Chaudhry) and the Department of Mathematical Sciences (Dr Bukiet) at the New Jersey Institute of Technology in Newark; the Department of Internal Medicine at the University of Padua in Italy (Dr Stecco); and the Veterans Affairs Medical Center in East Orange, New Jersey

(Dr Findley). Dr Findley is also a professor at the Rutgers New Jersey Medical School in Newark.

Financial Disclosures: None reported.

Address correspondence to Bruce Bukiet, PhD, Department of Mathematical Sciences, New Jersey Institute of Technology, University Heights, Newark, NJ 07102-1982.

E-mail: bukiet@njit.edu

Submitted

August 23, 2012;

revision received January 21, 2013;

accepted

January 28,2013
Context: More research is needed to understand the flow characteristics of hyaluronic acid (HA) during motions used in osteopathic manipulative treatment and other manual therapies.

Objective: To apply a 3-dimensional mathematical model to explore the relationship between the 3 manual therapy motions (constant sliding, perpendicular vibration, and tangential oscillation) and the flow characteristics of HA below the fascial layer.

Methods: The Squeeze Film Lubrication theory of fluid mechanics for flow between 2 plates was used, as well as the Navier-Stokes equations.

Results: The fluid pressure of HA increased substantially as fascia was deformed during manual therapies. There was a higher rate of pressure during tangential oscillation and perpendicular vibration than during constant sliding. This variation of pressure caused HA to flow near the edges of the fascial area under manipulation, and this flow resulted in greater lubrication. The pressure generated in the fluid between the muscle and the fascia during osteopathic manipulative treatment causes the fluid gap to increase. Consequently, the thickness between 2 fascial layers increases as well. Thus, the presence of a thicker fluid gap can improve the sliding system and permit the muscles to work more efficiently.

Conclusion: The mathematical model employed by the authors suggests that inclusion of perpendicular vibration and tangential oscillation may increase the action of the treatment in the extracellular matrix, providing additional benefits in manual therapies that currently use only constant sliding motions.

J Am Osteopath Assoc. 2013;113(8):600-610 doi:10.7556/jaoa.2013.021

$\mathrm{H}$ yaluronan or hyaluronic acid (HA) is found throughout the extracellular space of higher animals, in human skeletal muscle of the lower extremities, and in loose connective tissue. ${ }^{1,2}$ Fascia - a dense connective tissue that binds muscles, bones, and organs - forms a network of tissue throughout the body. The fascial network plays an important role in transmitting mechanical forces during changes in human posture to improve postural alignment and other expressions of musculoskeletal dynamics.

The deep fascia is a multilayered structure of dense and loose connective tissue, where HA produces a gliding interface in conjunction with the epimysium of the muscle. ${ }^{3}$ As revealed in a study by McCombe et al, ${ }^{4}$ higher concentrations of HA are localized in the muscular surface of the deep fascia. The inner gliding layer in the 
retinaculums of both the ankle and the wrist contain HAsecreting cells, ${ }^{5}$ reported by Ellis et $\mathrm{al}^{6}$ to be modified fibroblasts. Furthermore, Katzman et $\mathrm{al}^{7}$ found HAsecreting cells in the inner layer annular and cruciform pulleys in the hands of fresh, unembalmed elderly cadavers.

As viscosupplementation, HA is injected into joints to improve lubrication and clinical function. Researchers have investigated HA in osteopathic contexts, such as wound healing ${ }^{8}$ and osteoarthritis treatments. ${ }^{9,10}$ Assuming that the adjacent cartilage layers in a joint are impermeable to HA, Tadmor et $\mathrm{a}^{11}$ summarized the characteristics of HA within joints as follows:

- The role of HA is to assuage compression.

- HA is not expected to act as a good "boundary lubricant," but it increases the bulk viscosity of synovial fluid that in turn enhances its mode of lubrication.

- Viscosity of HA decreases considerably with the decreasing gap between the 2 surfaces in which it resides.

- With loading of the upper surface, the film thickness decreases, whereas with unloading, the film thickness increases.

When internal pressure within a fascial compartment surpasses venous pressure, the creation of compartment syndrome occurs, which is found in many different fascial compartments of the body, ${ }^{12}$ as well as in legs, ${ }^{13}$ arms, ${ }^{14}$ the back, ${ }^{15}$ and the abdomen. ${ }^{16,17}$ This syndrome occurs because the impermeability of fascia does not allow the fluid to escape, causing the collapse of venous outflow channels. Furthermore, during ultrasonographicguided injection of platelet-rich plasma into fascial layers, the fluid injected can be observed to increase the separation between adjacent layers. This plasma has a substantially lower molecular weight than HA does, supporting the notion that HA does not cross fascial layers. Thus, for the purposes of the present study, we consider the fascial layers to be impermeable to HA.

Manual therapy techniques - such as Rolfing (structural integration), massage with a mechanical vibrator, and fascial manipulation - are designed to manipulate fascial layers within the body. Therapists often claim that the increased fascial motion of these techniques results in beneficial effects.

In the present study, we explored the mechanical properties of 3 different motions used in manual therapy: constant sliding, perpendicular vibration, and tangential oscillation. Osteopathic manipulative treatment techniques often combine these basic motions. The degree of pressure to fascial layers varies greatly depending on the motions applied by therapists. Constant sliding (eg, Rolfing) involves a therapist applying a compressive and tangential force with a constant tangential velocity. Perpendicular vibration (eg, massage with a mechanical vibrator) affects the upper layer of the fascia by means of a massaging instrument with a specified frequency. With tangential oscillation (eg, fascial manipulation), the therapist applies rapid back-and-forth motions to affect the tissues.

The purpose of the present study was to apply a 3-dimensional mathematical model to evaluate the flow of HA around or within the fascia during constant sliding, perpendicular vibration, and tangential oscillation motions. In the process, we also intended to expand our conceptualization of HA behavior from adjacent impermeable cartilage layers to adjacent fascia layers. This model enables us to investigate the effect of the pressure generated by HA within the thin film between muscle and the deep fascia during these motions. We hypothesized that this pressure could be a potential mechanism for the clinical effects observed in manual therapy techniques. 


\section{Methods}

The squeeze film lubrication theory in fluid mechanics for flow between 2 plates is incorporated as a key part of the mathematical model. ${ }^{18}$ This theory describes the activity of fluid lubrication film enclosed between 2 surfaces in instances where 1 of those surfaces is subjected to pressure and tangential velocity.

The viscosity of HA is independent of shear rate in experiments using different frequencies and amplitudes, ${ }^{11}$ indicating Newtonian behavior of HA. A Newtonian fluid has a linear relationship between the stress (or force) applied to it and the resulting strain rate produced. Furthermore, HA has a constant viscosity of $5300 \mathrm{cP}$ in the temperature range of $22^{\circ} \mathrm{C}$ to $31^{\circ} \mathrm{C},{ }^{19}$ marking $\mathrm{HA}$ as a Newtonian fluid at room temperature. Also, experimental shear stress and shear strain data for HA given in the article by Truskey et $\mathrm{al}^{20(\mathrm{p} 115)}$ showed a linear relationship between these quantities, indicating Newtonian (or very weakly non-Newtonian) behavior (Figure 1).

Hyaluronic acid is present in the endomysium, perymisium, and lower layer of fascia and throughout the deep fascia. The film thickness of the HA was reported by Stecco et $\mathrm{al}^{3}$ to be approximately $0.05 \mathrm{~mm}$. Because this thickness is slightly below the limit of resolution of current musculoskeletal ultrasonography, we will analyze HA from a theoretical viewpoint until specific in vivo measures of the HA layer become available.

In applying the mathematical model, we assumed various dynamics of velocity. The velocity used in constant sliding is taken as a constant $0.1 \mathrm{~m} / \mathrm{s}$, a value obtained by means of discussions with therapists who specialize in the Rolfing technique. Typical handheld massagers operate at a low-end frequency of $15 \mathrm{~Hz}$ and high-end frequency of $60 \mathrm{~Hz}$ in sinusoidal motion. Consequently, these values were used as the frequency input in our consideration of perpendicular vibration. For tangential oscillation, sinusoidal motion with a frequency of 2 and $4 \mathrm{~Hz}$ was used, which was based on a practical estimate by Stecco and $\mathrm{Stecco}^{21}$ of the frequency typical in fascial manipulation manual therapy.

As observed by 1 of our investigators (A.S.), who worked with an ultrasonographer to measure the deep fascial layer, when a load is applied on the surface of the skin, the fascial layer below deforms, creating a slope between the upper and the lower fascial layer. The resulting "wedge" that is created in the deformed state

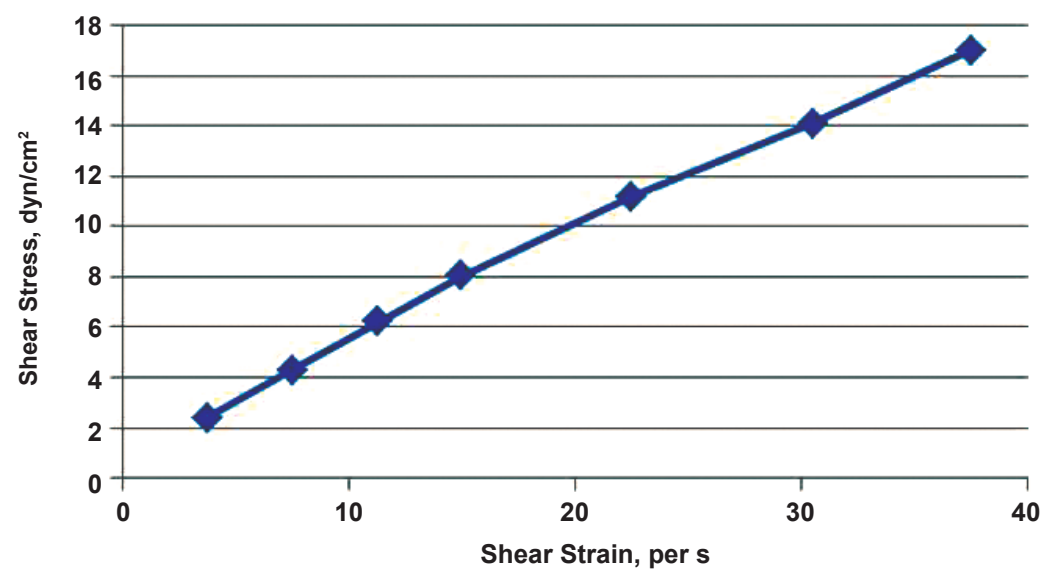

Figure 1.

The linear relationship between rates of shear stress and shear strain for hyaluronic acid. 
generates pressure within the fluid film when the fluid passes through the wedge. This pressure can "lift" the upper fascial layer in the same way that water between a tire and the road surface can lift a moving car, causing the tire to lose traction with the road surface (Figure 2). The faster the car is moving, the greater is the fluid pressure. This model of fascia and HA during manual therapy is consistent with squeeze film lubrication theory of fluid mechanics.

In considering Figure 2, we apply the Navier-Stokes equations in 3 dimensions along with the continuity equation in the following manner:

$$
\text { (1) } \begin{gathered}
\rho\left(\frac{\partial u}{\partial t}+u \frac{\partial u}{\partial x}+v \frac{\partial u}{\partial y}+w \frac{\partial u}{\partial z}\right)=-\frac{\partial p}{\partial x}+\rho g_{x}+\mu\left(\frac{\partial^{2} u}{\partial x^{2}}+\frac{\partial^{2} u}{\partial y^{2}}+\frac{\partial^{2} u}{\partial z^{2}}\right) \\
\rho\left(\frac{\partial v}{\partial t}+u \frac{\partial v}{\partial x}+v \frac{\partial v}{\partial y}+w \frac{\partial v}{\partial z}\right)=-\frac{\partial p}{\partial y}+\rho g_{y}+\mu\left(\frac{\partial^{2} v}{\partial x^{2}}+\frac{\partial^{2} v}{\partial y^{2}}+\frac{\partial^{2} v}{\partial z^{2}}\right) \\
\rho\left(\frac{\partial w}{\partial t}+u \frac{\partial w}{\partial x}+v \frac{\partial w}{\partial y}+w \frac{\partial w}{\partial z}\right)=-\frac{\partial p}{\partial z}+\rho g_{z}+\mu\left(\frac{\partial^{2} w}{\partial x^{2}}+\frac{\partial^{2} w}{\partial y^{2}}+\frac{\partial^{2} w}{\partial z^{2}}\right) .
\end{gathered}
$$

For equation (1), $u, v$, and $w$ are velocities in the $x, y$, and $z$ directions, respectively; $p$ is the hydrostatic pressure, $\rho$, the density of the fluid; $g_{x}, g_{y}$, and $g_{z}$, are gravity accelerations along the $x, y$, and $z$ directions; and $\mu$ is the viscosity.

The continuity equation for an incompressible fluid is expressed as the following:

(2)

$$
\frac{\partial u}{\partial x}+\frac{\partial v}{\partial y}+\frac{\partial w}{\partial z}=0
$$

\section{Boundary Conditions}

In Figure 3, the lower surface at $y=0$ is stationary with a velocity $u($ at $y=0)=0$. The upper surface at $y=h$ moves with velocity $u=U$. In the $z$ direction, the boundary conditions for the velocity $w$ at $y=0$ is $w($ at $y=0)=0$ and at the upper surface, $y=h$, the velocity is $\mathrm{w}($ at $y=h)=0$. The pressure along the edges is assumed to be $p=0$.

Using equations (1) and (2) together with the boundary conditions, the pressure distribution for different massaging techniques can be obtained from the following equation:

(3)

$$
\frac{1}{\mu}\left[\frac{\partial}{\partial x}\left(h^{3} \frac{\partial p}{\partial x}\right)+\frac{\partial}{\partial z}\left(h^{3} \frac{\partial p}{\partial z}\right)\right]=6 U \frac{\partial h}{\partial x}+12 \frac{\partial h}{\partial t}
$$

\section{Results}

\section{Constant Sliding}

In the sliding technique (Figure 3), a tangential force on the upper layer of fascia is applied with a velocity $U$. Therefore, the vertical velocity $\partial h / \partial t$ is ignored in equation (3). Then the partial differential equation (3) simplifies to the following equation: $\frac{1}{\mu}\left[\frac{\partial}{\partial x}\left(h^{3} \frac{\partial p}{\partial x}\right)+\frac{\partial}{\partial z}\left(h^{3} \frac{\partial p}{\partial z}\right)\right]=6 U \frac{\partial h}{\partial x}$.

The boundary conditions are applied to equation (4) and then solved numerically (by using FlexPDE software

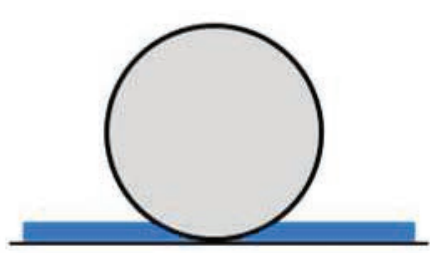

A

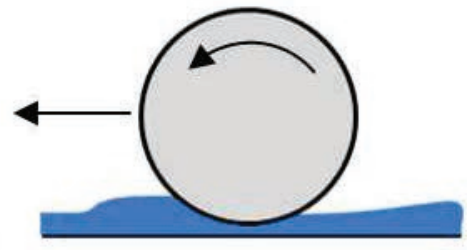

B
Figure 2.

The squeeze film lubrication theory, shown as an automobile tire in a static state (A) and in motion (B) on a road topped with a thin film of water (blue). The motion creates a "wedge," or slope, and generates pressure in the fluid film when the fluid passes through the wedge. This effect can be applied to how hyaluronic acid acts within the fascia. 


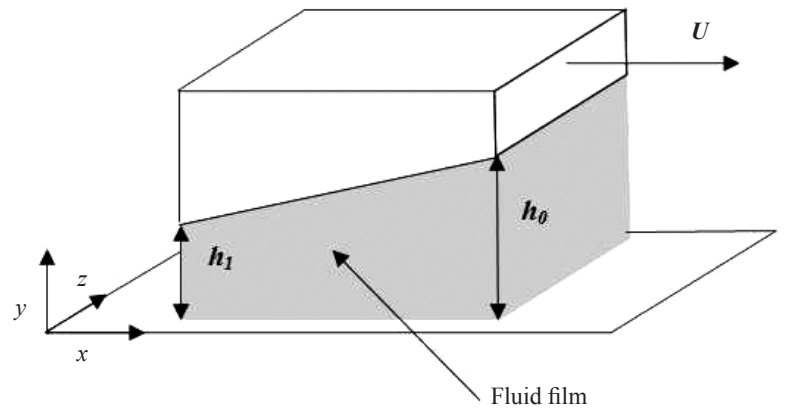

Figure 3.

Squeeze film model of constant sliding therapeutic motion. Tangential force on the upper layer of the fascia is applied with a horizontal velocity $U ; h_{0}$ is the film thickness at the right edge of the wedge, and $h_{1}$ is the thickness at the left edge.
[PDE Solutions Inc]) to determine the variation of pressure in the HA in the $x$ and $z$ directions. Because the fluid film thickness varies from site to site in the body, we assume a film thickness of $100 \mu \mathrm{m}$ at the left end and 80 $\mu \mathrm{m}$ at the right end for the purpose of illustration. The centerline pressure contours for the sliding technique on a $25 \times 25 \mathrm{~mm}^{2}$ fascial sheet and with a sliding velocity of $0.1 \mathrm{~m} / \mathrm{s}$ is presented in Figure 4. The peak pressure of $0.17 \mathrm{MPa}$ occurs near, but clearly to the right of, the center of the sheet. The pressure decreases to zero at the edges as prescribed.

\section{Perpendicular Vibration}

Therapists will at times use a mechanical massager to give perpendicular vibrations to the upper layer of fascia, which are then transmitted to the lower layer (Figure 5). When the upper layer is deformed downward, fluid is squeezed out of the gap in the $x$ and $z$ directions. In this case, as there is no tangential velocity $(U=0)$, we ignore $U$ in equation (3) and instead use the vertical velocity, $\partial h / \partial t$, where $h$ at any time $t$ is $h=h_{0}-A \sin ^{2} \omega t$ and thus $\partial h / \partial t=A \omega \sin 2 \omega t$, where $A$ is the amplitude (ie, the maximum displacement of the fascia). $A$ must be less than the thickness, $h_{0}$, of the film. The vibration frequency in hertz is $f=\omega / 2 \pi$, where $\omega$ is the angular frequency of vibration. Equation (3) then becomes the following:

(5)

$$
\frac{1}{\mu}\left[\frac{\partial}{\partial x}\left(h_{0}^{3} \frac{\partial p}{\partial x}\right)+\frac{\partial}{\partial z}\left(h_{0}^{3} \frac{\partial p}{\partial z}\right)\right]=12[A \omega \sin (2 \omega t)] .
$$

The pressure distribution for a vibration frequency of $15 \mathrm{~Hz}$ and amplitude, A, of $20 \mu \mathrm{m}$ is plotted in Figure 6 . As in constant sliding, the fluid viscosity is taken as $5300 \mathrm{cP}$, and the vibrations are applied over a fascial sheet of $25 \times 25 \mathrm{~mm}^{2}$ area. The fluid film thickness is taken as $h_{0}=100 \mu \mathrm{m}$.

The peak pressure occurs at the center and has a value of 5.7 MPa. The peak pressure in this case is a function of the frequency of vibration. As can be seen in Figure 7, increasing the frequency by a factor of 4 to $60 \mathrm{~Hz}$ also increases the pressure by a factor of 4 to $22.8 \mathrm{MPa}$. In general, therefore, an increase in vibration frequency will increase the peak pressure by a proportional amount, as there is a linear relationship between frequency and peak pressure.

\section{Tangential Oscillation}

In the third and final situation, we investigated the pressure distribution by using the tangential oscillation technique. In this form of fascial manipulation, the therapist provides a perpendicular load with a back-and-forth oscillation; $U(t)$ is now a function of time (Figure 8), rather than the constant forward sliding velocity, $U$, of constant sliding.

Equation (3) is now modified to account for the changing velocity in the $x$ direction and becomes the following: 


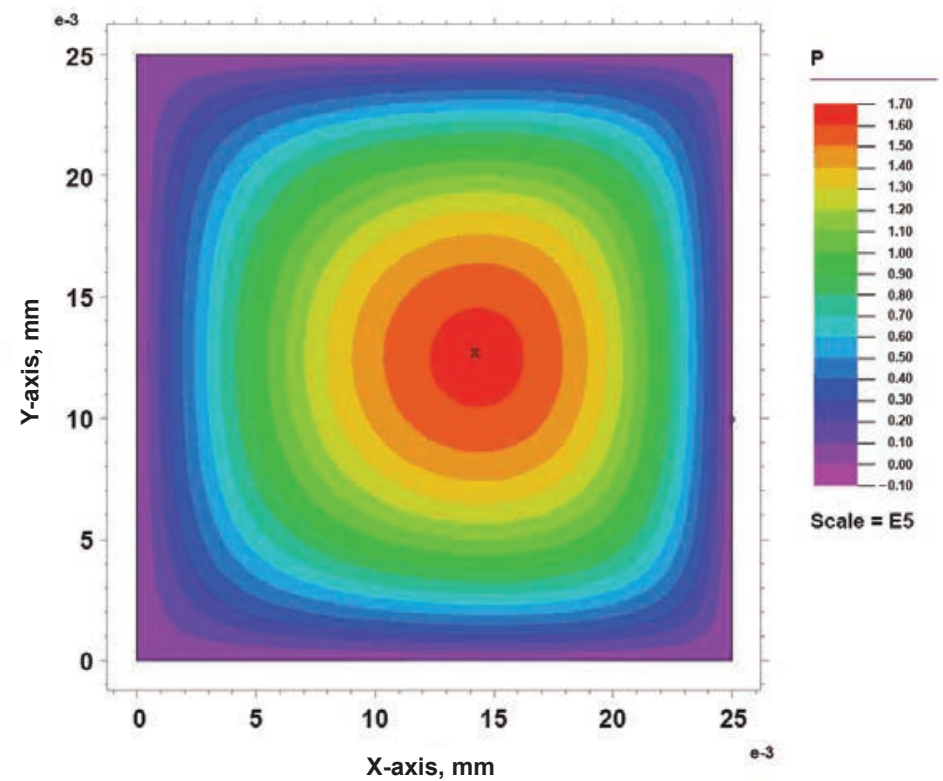

Figure 4.

Pressure distribution during constant sliding therapeutic motion at a velocity of $0.1 \mathrm{~m} / \mathrm{s}$.

(6) $\frac{1}{\mu}\left[\frac{\partial}{\partial x}\left(h^{3} \frac{\partial p}{\partial x}\right)+\frac{\partial}{\partial z}\left(h^{3} \frac{\partial p}{\partial z}\right)\right]=6 U \frac{\partial h}{\partial x} d \omega \cos \omega t$

where $d$ is the maximum sliding distance in the $x$ direction. For this example, we take $d$ to be $25 \mathrm{~mm}$ and the frequency of oscillation as $2 \mathrm{~Hz}$. All other parameters are equal to those used for the constant sliding situation discussed previously.

As shown in Figure 9, the peak pressure is $0.54 \mathrm{MPa}$ for the parameters used. If the frequency of oscillation is doubled to $4 \mathrm{~Hz}$, the peak pressure is also again approximately doubled to $1.05 \mathrm{MPa}$, as shown in Figure 10.

\section{Comment}

A slope needs to be present to generate a fluid pressure gradient during constant sliding motion, as can be seen in equations (4) and (6). That is, there must be a difference in film thickness between the right edge and the left edge. If the film thickness is constant throughout, there will be no fluid pressure gradient generated. As observed during

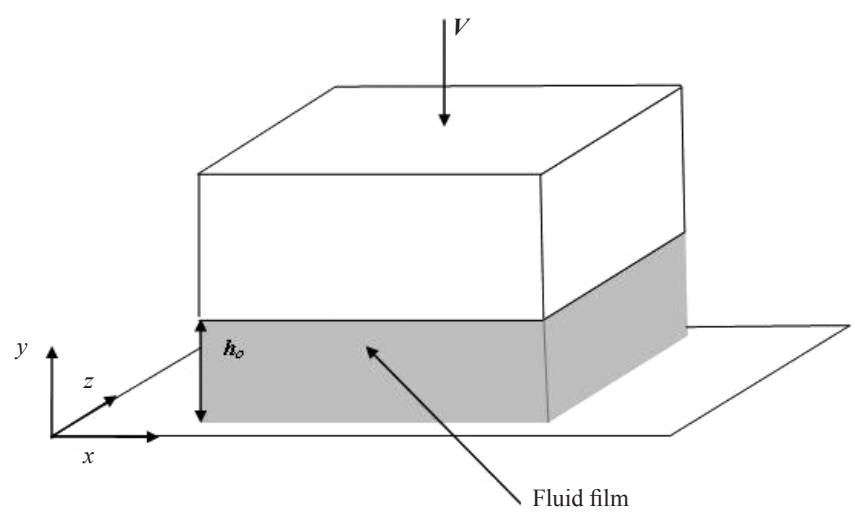

Figure 5.

Squeeze film model for perpendicular vibration. Vertical velocity on the upper layer of the fascia is applied as depicted by $V ; h_{0}$ is the film thickness; $V$ and $h_{0}$ are functions of time. 

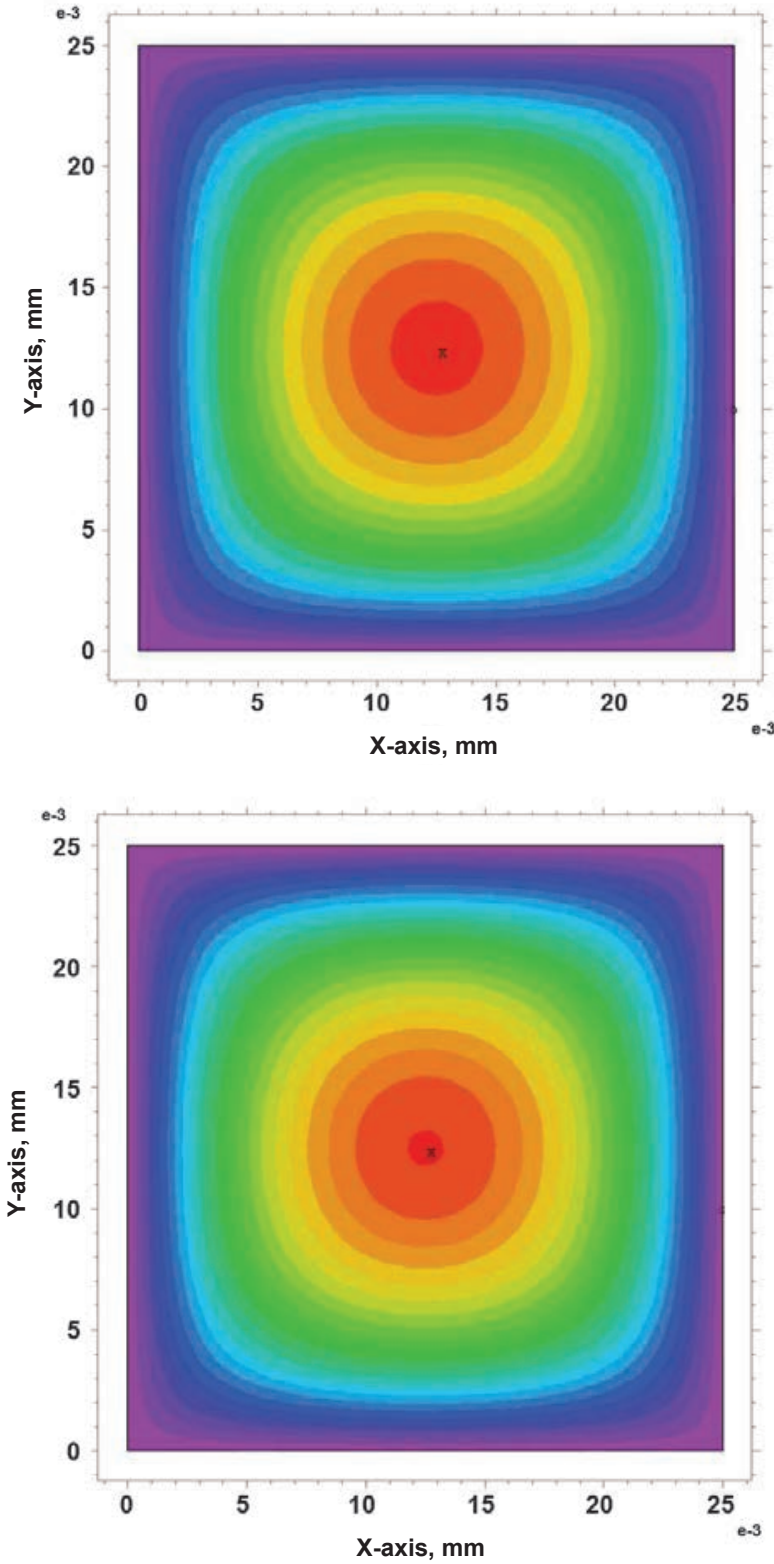

ultrasonographic imaging, when a load is applied on the epidermis, deformation throughout the fascia varies between the area immediately under the load and the surrounding tissues. In the case of perpendicular vibration, there is no slope component, as can be seen in equation (5). Only the change in height due to the vibratory

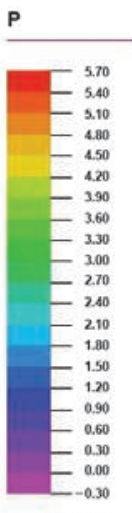

Figure 6.

Pressure distribution during perpendicular vibration at $15 \mathrm{~Hz}$ and $20 \mu \mathrm{m}$ amplitude.

Figure 7.

Pressure distribution during perpendicular vibration at $60 \mathrm{~Hz}$ and $20 \mu \mathrm{m}$ amplitude. 


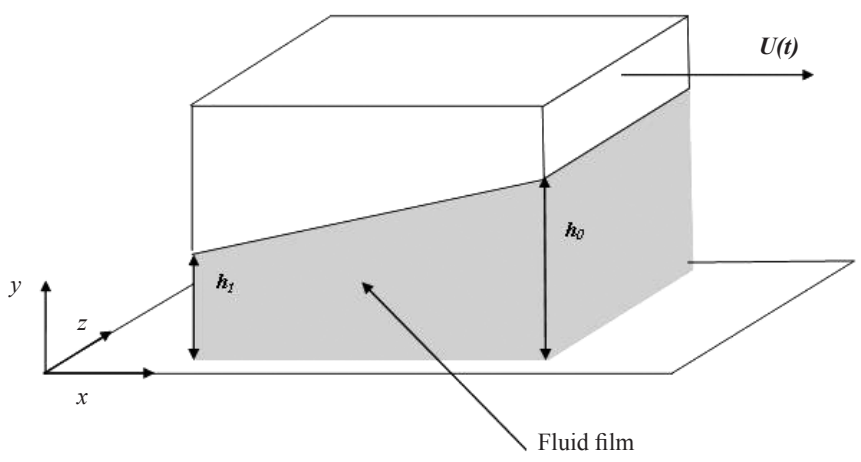

\section{Figure 8.}

Squeeze film model of tangential oscillation. Tangential force on the upper layer of the fascia is applied with a sinusoidal horizontal velocity $U(t) ; h_{0}$ is the film thickness at the leading edge of the wedge, and $h_{1}$ is the thickness at the trailing edge.
$25 \mathrm{~mm}^{2}$. As can be seen, constant sliding motion results in the lowest fluid pressure generated. Whereas the fluid pressure is highly dependent on the velocity at which the therapy is applied (ie, higher velocities generate a greater fluid pressure), in practice, velocities greater than $0.1 \mathrm{~m} / \mathrm{s}$ are generally not applied. Tangential oscillation (ie, back-and-forth sliding) generates a slightly greater level of fluid pressure because greater velocities can be more easily applied over a shorter distance. As the frequency of the motion increases, the peak fluid pressure also increases linearly. Finally, it can be seen that perpendicular vibration motion causes the highest peak pressures. At $60 \mathrm{~Hz}$, the peak fluid pressure is many times greater than for either constant sliding or tangential oscillation. Again, this difference is due to the greater velocities that can be used in applying vibration vs sliding. We stress, however, that as greater maximum pressures are generated during oscillatory motion — such as perpendicular vibration and back-and-forth sliding (tangential oscillation)_-pressure oscillates in time. In constant sliding

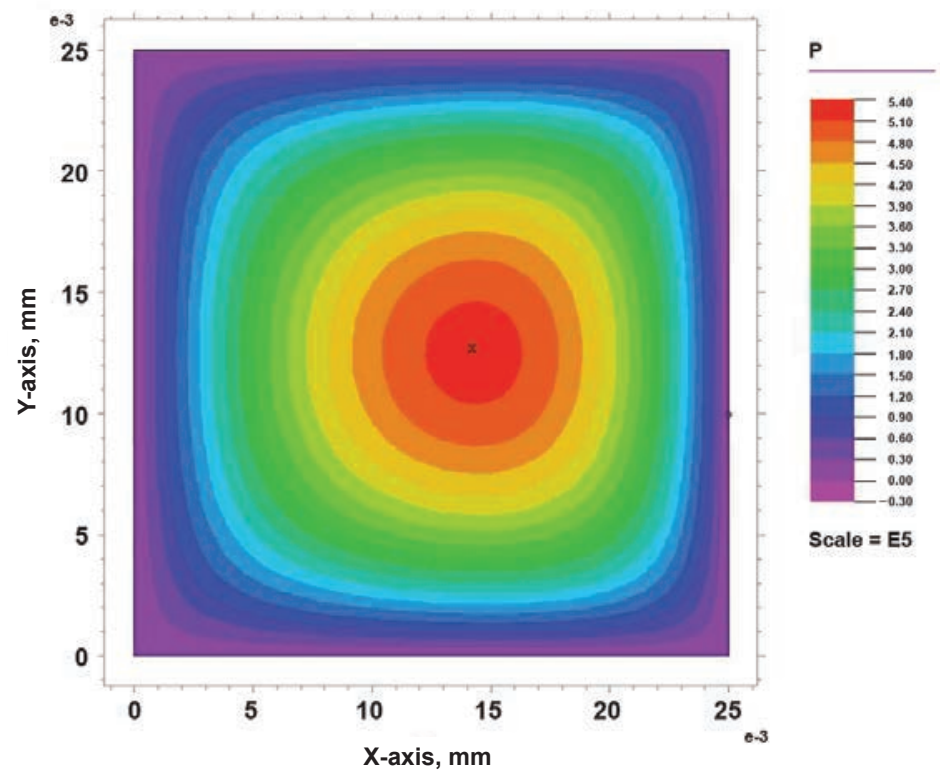

Figure 9.

Pressure distribution for tangential oscillation at $2 \mathrm{~Hz}$ with a distance of $25 \mathrm{~mm}$. 


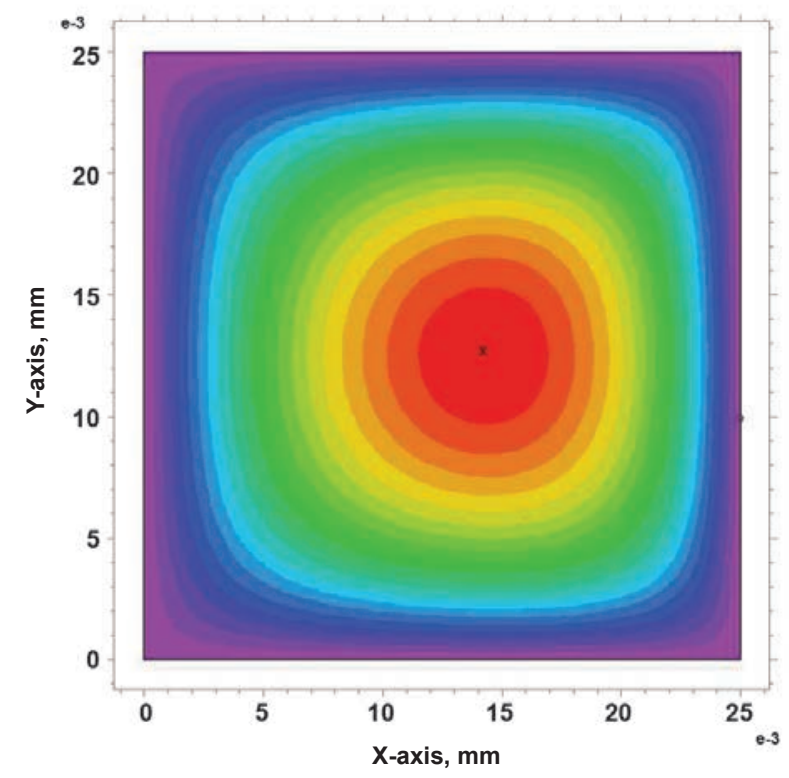

motion, the peak pressure is lower, but it is maintained at the same level throughout the sliding motion. The fluid pressure generated between the 2 layers causes the fluid gap to increase and, consequently, the thickness between 2 fascia layers to increase. The presence of a thicker fluid gap can improve the sliding system and permit the muscles to work more efficiently. Each motion may have its own advantages. Future studies should investigate each
$\mathbf{P}$

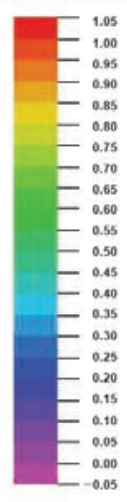

Figure 10.

Pressure distribution for tangential oscillation at $4 \mathrm{~Hz}$ with a distance of $25 \mathrm{~mm}$. motion in greater detail.

With perpendicular vibration, we assumed the amplitude of oscillation remained constant as the frequency was adjusted from $15 \mathrm{~Hz}$ to $60 \mathrm{~Hz}$. It should be noted, however, that in practice the amplitude changes non-linearly as the frequency of oscillation of the mechanical vibrator is increased or decreased. As the frequency increases, the amplitude must decrease.

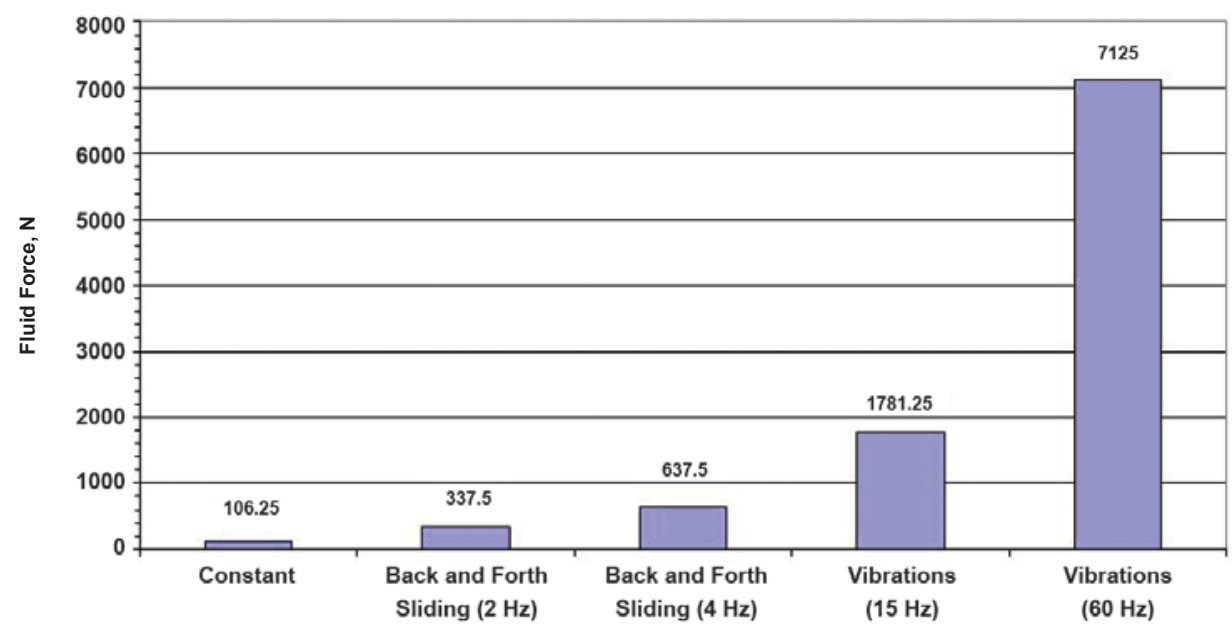

Figure 11.

Comparison of peak pressure rates for constant sliding, perpendicular vibration, and tangential oscillation. 
Another implication of the mathematical model is that it provides a possible explanation for the decrease in adhesion between different tissues, a condition reported by therapists and patients alike. It is not clear whether a change in lubrication due to HA will continue after manual therapeutic motions have stopped. Subsequent sessions may be required to continue lubrication unless other longer-lasting structural changes are taking place; such changes are similar to ones that occurred in the connective tissue structures that allow tendon sliding, as noted by Guimberteau et al. ${ }^{22}$

Current musculoskeletal ultrasonography can produce images of fluid layers of 100 to $200 \mu \mathrm{m}$. Nevertheless, anatomic investigations at even higher resolution will be needed to evaluate structural connective tissue changes by using in vitro techniques such as sheet plastination ${ }^{23}$ or second harmonic imaging. ${ }^{24}$

Our results suggest that use of a mechanical massager may produce better gliding between the different anatomical structures than hands-only therapy. We believe that therapists who use other mechanical tools - such as the 6 stainless steel instruments used with the Graston technique - may also claim greater benefits than manual therapy alone. These tools are used to apply pressure on a much smaller area compared with the therapist's finger or hand, and the benefits may be due to a greater pressure gradient in the HA layer. Future studies should seek measurements of loading and shear forces, as well as HA layer thickness, during manual therapy, which can then be used to improve the reliability of our results and refine current manual therapies.

\section{Conclusion}

The mathematical model suggests that inclusion of perpendicular vibration and tangential oscillation may provide additional benefits in manual therapies that currently use only constant sliding motions.

\section{References}

1. Laurent TC, Fraser JRE. Hyaluronan. FASEB J. 1992;6(7):23972404.

2. Piehl-Aulin K, Laurent C, Engström-Laurent A, Hellström $S$, Henriksson J. Hyaluronan in human skeletal muscle of lower extremity: concentration, distribution, and effect of exercise. J Appl Physiol. 1991;71(6):2493-2498.

3. Stecco C, Stern R, Porzionato A, et al. Hyaluronan within fascia in the etiology of myofascial pain. Surg Radiol Anat. 2011;33(10):891896.

4. McCombe D, Brown T, Slavin J, Morrison WA. The histochemical structure of the deep fascia and its structural response to surgery. $J$ Hand Surg Br. 2001;26(2):89-97.

5. Klein DM, Katzman BM, Mesa JA, Lipton JF, Caligiuri DA. Histology of the extensor retinaculum of the wrist and the ankle. $J$ Hand Surg Am. 1999;24(4):799-802.

6. Ellis FD, Seiler JG III, Sewell CW. The second annular pulley: a histologic examination. J Hand Surg Am. 1995;20(4):632-635.

7. Katzman BM, Klein DM, Garven TC, Caligiuri DA, Kung J. Comparative histology of the annular and cruciform pulleys. $J$ Hand Surg Br. 1999;24(3):272-274.

8. Dubrow CM. Beneficial effects of protein-specific hyaluronic acid on wound healing. J Am Osteopath Assoc. 1972;72(2):191-193.

9. Iannitti T, Lodi D, Palmieri B. Intra-articular injections for the treatment of osteoarthritis: focus on the clinical use of hyaluronic acid. Drugs R D. 2011;11(1):13-27.

10. O'Connell JA. Myofascial release approach. In: Chila AG, executive ed. Foundations of Osteopathic Medicine. 3rd ed. Baltimore, MD; Lippincott Williams \& Wilkins; 2011:698-727.

11. Tadmor R, Chen N, Israelachvili JN. Thin film rheology and lubricity of hyaluronic acid solutions at a normal physiological concentration. J Biomed Mater Res. 2002;61(4):514-523.

12. McDonald S, Bearcroft P. Compartment syndromes. Sem Musculoskelet Radiol. 2010;14(2):236-244.

13. King TW, Lerman OZ, Carter JJ, Warren SM. Exertional compartment syndrome of the thigh: a rare diagnosis and literature review. J Emerg Med. 2010;39(2):e93-e99. doi:10.1016/j. jemermed.2007.10.081.

14. Leversedge FJ, Moore TJ, Peterson BC, Seiler JG III. Compartment syndrome of the upper extremity [review]. $J$ Hand Surg Am. 2011;36(3):544-559.

15. Paryavi E, Jobin CM, Ludwig SC, Zahiri H, Cushman J. Acute exertional lumbar paraspinal compartment syndrome. Spine (Phila Pa 1976). 2010;35(25):E1529-E1533. doi:10.1097/ BRS.0b013e3181ec4023.

16. Grossman LC, Michalakis KG, Browne H, Payson MD, Segars JH. The pathophysiology of ovarian hyperstimulation syndrome: an unrecognized compartment syndrome. Fertil Steril. 2010;94(4):1392-1398. 
17. Mayer D, Veith FJ, Lachat M, Pfammatter T, Hechelhammer L, Rancic Z. Abdominal compartment syndrome. Minerva Chir. 2010;65(3):329-346.

18. Panton RL. Incompressible Flow. 2nd ed. New York, NY: John Wiley \& Sons; 1996.

19. Lee H, Park TG. Photo-crosslinkable, biomimetic, and thermosensitive pluronic grafted hyaluronic acid copolymers for injectable delivery of chondrocytes. J Biomed Mater Res A. 2009;88(3):797806.

20. Truskey GA, Yuan F, Katz DF. Transport Phenomena in Biological Systems. 2nd ed. Upper Saddle River, NJ: Pearson Prentice Hall; 2009.

21. Stecco L, Stecco C. Fascial Manipulation: Practical Part. Day JA, trans. Padova, Italy: Piccin; 2009.
22. Guimberteau JC, Delage JP, Wong J. The role and mechanical behavior of the connective tissue in tendon sliding. Chir Main. 2010;29(3):155-166.

23. Nash LG, Nicholson H, Lee AS, Johnson GM, Zhang M. Configuration of the connective tissue in the posterior atlantooccipital interspace: a sheet plastination and confocal microscopy study. Spine (Phila Pa 1976). 2005;30(12):1359-1366.

24. Rivard M, Laliberté M, Bertrand-Grenier A, et al. The structural origin of second harmonic generation in fascia. Biomed Opt Express. 2010;2(1):26-36.

๑) 2013 American Osteopathic Association

\section{JAOA Implements DOls}

Articles published in The Journal of the American Osteopathic Association (JAOA) are now registered with the DOI (digital object identifier) system. Like URLs, DOls can be used to quickly locate specific content online. However, unlike URLs, DOls never change or break over time. Readers of the JAOA can find DOls after the abstracts in research articles and after the final paragraphs in communications and special feature articles (eg, letters, clinical images). 